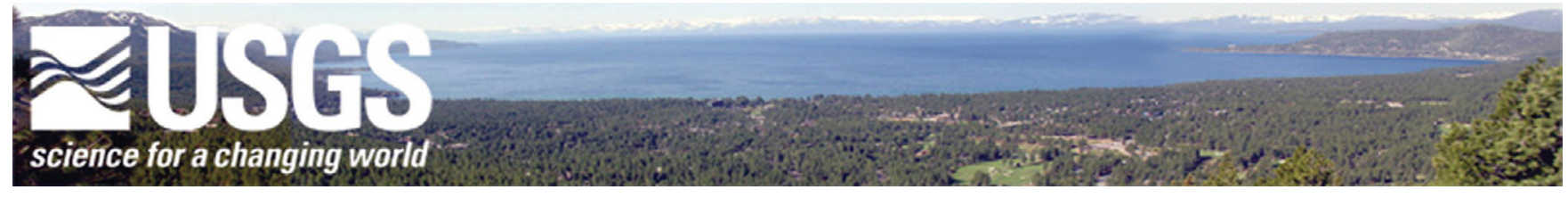

\title{
Historical Orthoimagery of the Lake Tahoe Basin
}
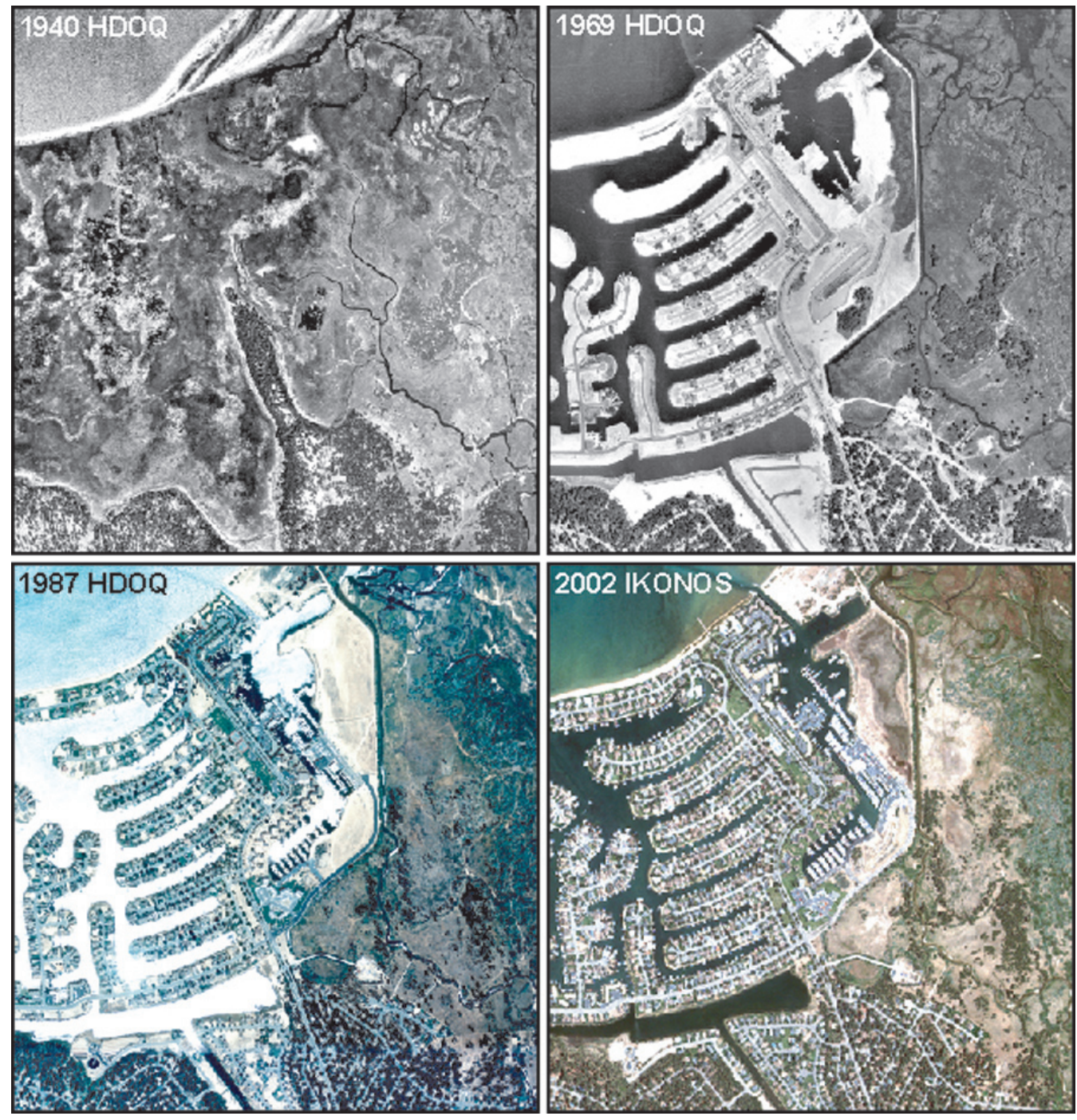

Data Series 376 


\section{COVER}

Historical digitial orthophotos (1940, 1969, 1987) and Ikonos imagery (2002) showing temporal land-cover change in South Lake Tahoe near the mouth of the Upper Truckee River. 


\section{Historical Orthoimagery of the Lake Tahoe Basin}

By Christopher E. Soulard and Christian G. Raumann

Data Series 376

U.S. Department of the Interior

U.S. Geological Survey 


\section{U.S. Department of the Interior \\ DIRK KEMPTHORNE, Secretary}

\section{U.S. Geological Survey \\ Mark D. Myers, Director}

\section{U.S. Geological Survey, Reston, Virginia: 2008}

For product and ordering information:

World Wide Web: http://www.usgs.gov/pubprod

Telephone: 1-888-ASK-USGS

For more information on the USGS--the Federal source for science about the Earth, its natural and living resources, natural hazards, and the environment:

World Wide Web: http://www.usgs.gov

Telephone: 1-888-ASK-USGS

Any use of trade, product, or firm names is for descriptive purposes only and does not imply endorsement by the U.S. Government.

Although this report is in the public domain, permission must be secured from the individual copyright owners to reproduce any copyrighted materials contained within this report.

Suggested citation:

Soulard, C.E., and Raumann, C.G., 2008, Historical orthoimagery of the Lake Tahoe basin: U.S. Geological Survey Data Series 376, $7 \mathrm{p}$.

Any use of trade, product, or firm names is for descriptive purposes only and does not imply endorsement by the U.S. Government.

Although this report is in the public domain, permission must be secured from the individual copyright owners to reproduce any copyrighted material contained within this report.

Cataloging-in-publication data are on file with the Library of Congress (http://www.loc.gov/). 


\section{Table of Contents}

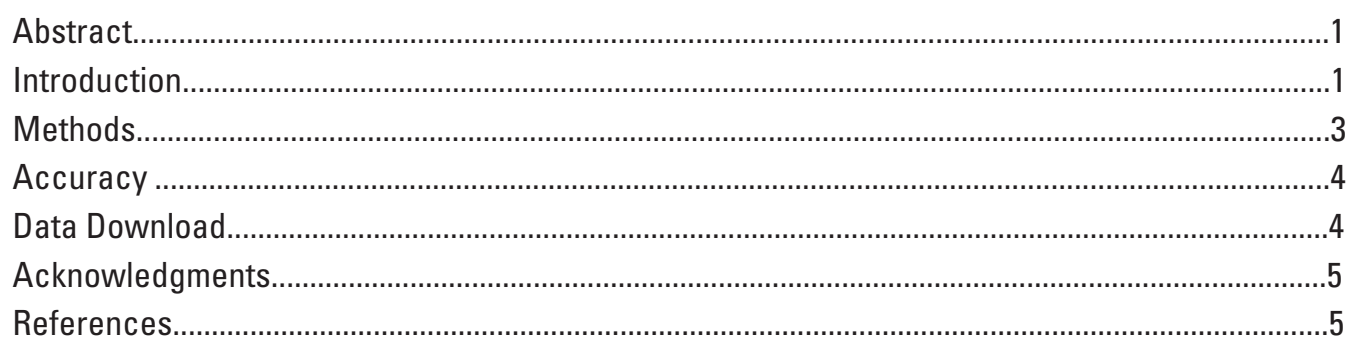

\section{Figures}

Figure 1. The Lake Tahoe Basin is located in the Sierra Nevada Mountains on the border between California and Nevada.

.2

Figure 2. Four dates $(1940,1969,1987,2002)$ of temporal land-use/land-cover data derived from HDOs and satellite imagery........................................................................................

Figure 3. Footprint of HDO/HDOO data for the southern Lake Tahoe basin for 1940 and 1987.........6

Figure 4. Footprint of HDO/HDOO data for the Lake Tahoe basin for 1969 ......................................6 
Blank page 


\title{
Historical Orthoimagery of the Lake Tahoe Basin
}

\author{
By Christopher E. Soulard and Christian G. Raumann
}

\section{Abstract}

The U.S. Geological Survey (USGS) Western Geographic Science Center has developed a series of historical digital orthoimagery (HDO) datasets covering part or all of the Lake Tahoe Basin. Three datasets are available: (A) 1940 HDOs for the southern Lake Tahoe Basin, (B) 1969 HDOs for the entire Lake Tahoe Basin, and (C) 1987 HDOs for the southern Lake Tahoe Basin. The HDOs (for 1940, 1969, and 1987) were compiled photogrammically from aerial photography with varying scales, camera characteristics, image quality, and capture dates. The resulting datasets have a 1-meter horizontal resolution. Precision-corrected Ikonos multispectral satellite imagery was used as a substitute for HDOs/DOQs for the 2002 imagery date, but these data are not available for download in this series due to licensing restrictions. The projection of the HDO data is set to UTM Zone 10, NAD 1983. The data for each of the three available dates are clipped into files that spatially approximate the 3.75-minute USGS quarter quadrangles (roughly 3,000 to 4,000 hectares), and have roughly 100 pixels (or 100 meters) of overlap to facilitate combining the files into larger regions without data gaps. The files are named after 3.75-minute USGS quarter quadrangles that cover the same general spatial extent. These files are available in the ERDAS Imagine (.img) format.

\section{Introduction}

Researchers with the U.S. Geological Survey (USGS) Western Geographic Science Center, the USGS Nevada Water Science Center, and the Desert Research Institute have recently completed an interdisciplinary research project in the Lake Tahoe Basin in California and Nevada designed to (1) map the current and historical state of the land surface, (2) analyze patterns, rates, and trends in urbanization and land-use change using GIS and other tools, and (3) assess the causes of land-use change and the possible implications to water quality and ecosystem health (Raumann and others, 2008). This research focused on the southern Lake Tahoe Basin that includes the Upper Truckee River, Trout Creek, and Bijou Creek watersheds and three intervening areas that directly contribute to lake inflows (27,937-ha area). The USGS is cur- rently in the process of expanding this research to the entire Lake Tahoe Basin (roughly 83,500-ha area) (fig. 1).

Although earlier research efforts had been made to understand how Lake Tahoe functions and to what extent humans have affected the surrounding landscape, large-scale geospatial landcharacterization data did not exist for any part of the Lake Tahoe Basin until this project began. To accomplish the goal of land characterization, a comprehensive data-collection and production effort was required. The first step was to build a database of vertically integrated historical and current imagery from which the various land-characterization datasets could be derived by using photograph-interpretation and remote-sensing techniques.

Historical aerial photographs are a very valuable imagery source available for high-resolution temporal Earth-surface studies that are used in a wide array of applications. However, unique photogrammetric challenges are inherent in working with historical aerial photographs, which commonly have varying scales, camera characteristics, coverage areas, image quality, and capture dates. By integrating standardized methods developed by the National Digital Orthophoto Program with modernized image processing techniques, which together meet National Map Accuracy Standards (as described further in the Accuracy section), the USGS has successfully produced historical digital orthophotos (HDOs) from historical aerial photographs in the Lake Tahoe Basin.

A "digital orthophoto" is defined (U.S. Geological Survey, 1996) as "a georeferenced image prepared from a perspective photograph, or other remotely sensed data in which the displacement within the image due to sensor orientation and terrain relief has been removed... a digital orthophoto is created by scanning an aerial photograph transparency (diapositive) with a precision image scanner. The scanned data file is then digitally rectified to an orthographic projection by processing each image pixel through photogrammetric space resection equations. This process requires, as input, ground control points acquired from ground surveys or developed in aerotriangulation (AT), conjugate photo-coordinates of ground control, camera-orientation parameters, and a digital elevation model (DEM)." The digital orthophotos created through this project adhere to the same requirements for source data and production processes.

HDOs for the years 1940, 1969, and 1987 were produced by using multiple sources of archived aerial photographs. Initial efforts required image rectification of 3.75-minute 


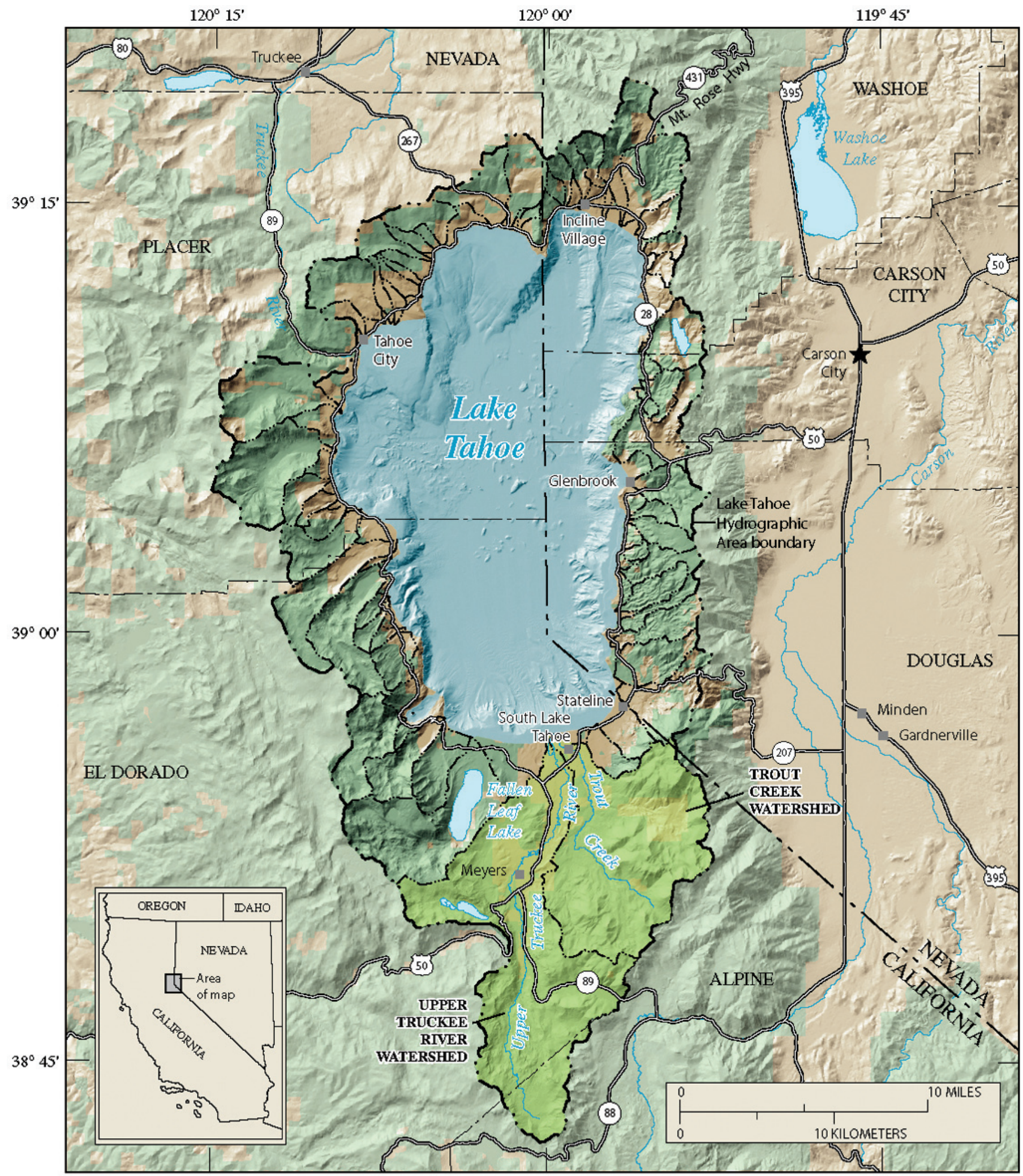

Base from U.S. Geological Survey digital data, 1:100,000, 1968-85 Universal Transverse Mercator projection,

Zone 11

Figure 1. The Lake Tahoe Basin is located in the Sierra Nevada Mountains on the border between California and Nevada. The hydrographic basin is outlined in black. The initial study area, that included the Upper Truckee River, Trout Creek, and Bijou Creek watersheds, is located in the southern part of the Lake Tahoe Basin (displayed as a light green). 
quadrangles (roughly 3,000 to 4,000 hectares) of HDOs (or HDOQs) for southern Lake Tahoe, but changes in the project's scope have expanded these efforts to the entire Lake Tahoe Basin. The aerial photographs used to produce the HDOs are as follows: 1940 U.S. Forest Service (USFS) black-andwhite photographs (CNL, July 1940), 1969 USGS black-andwhite photographs (VCHH, August 1969), and 1987 USFS natural-color photographs (Lake Tahoe Basin Management Unit, USFS 615170, July 1987). Precision-corrected Ikonos multispectral satellite imagery (1-m pixel size, acquired July 2002) was used as a substitute for HDOs/digital orthophoto quadrangles (DOQs) for the latest imagery date (Ikonos imagery is not available for download in this series due to licensing restrictions).

These HDOs have been utilized for interdisciplinary landscape-change research in the Lake Tahoe Basin. Four dates $(1940,1969,1987,2002)$ of temporal land-use/landcover, transportation-network, impervious-surface-area, and stream-channel-morphology data were derived from HDOs and satellite imagery for the Lake Tahoe Basin (fig. 2). These datasets are correlated with past and current water-quality data to measure the extent and effects of anthropogenic disturbances (Raumann and others, 2008). This project demonstrates the significant value of the distinctive data record of historical aerial photographs, as well as the need for using the HDO format to make these images functional within geographic information systems (GIS).

\section{Methods}

Before initiating HDO production, several issues regarding the nature of the photography needed to be resolved to determine the most appropriate photography dates to use. These issues included: (1) the quality of the film diapositive or photographic print to be scanned; (2) the existence of any camera data, including information regarding the calibrated focal length, flight height, flight direction, scale, and calibrated fiducial measurements; and (3) the ability to acquire control data (for example, DOQs, USGS DEMs, and USGS 7.5-minute topographic-quadrangle maps) that coincided with each of the historical photograph dates. The most important consideration that can affect HDO production is the presence and distribution of well-defined photo-identifiable feature points shared by both the historical photographs and the data used for control (primarily DOQs). Changes in the landscape throughout time can affect the production team's ability to identify well-defined ground control points shared by both the historical photographs and the control data, and the lack of common points can make orthorectification largely inaccurate. Although more historical photography exists for the Lake Tahoe Basin beyond the 1940, 1969, and 1987 dates used in this study, these dates were determined to be the most appropriate based on the above criteria.
Initial steps of HDO production included project planning, source-data research, and data acquisition. Data research and acquisition steps included obtaining existing standard USGS first-generation DOQs, USGS DEMs, published USGS 7.5-minute topographic-quadrangle maps, flightline diagrams, historical aerial photographs, and camera-calibration reports for the historical aerial photographs.

The photograph centers and extents were plotted on 7.5-minute topographic quadrangle maps for general reference and orientation to the data used for control. This photograph layout also helped determine the optimum image coverage for the 3.75-minute image mosaic. The number of single orthorectified images, or "chips," needed to make a HDOQ depends on the photographic scale and the location of photograph exposure. This varied considerably between each dataset, since the photographic scale (from 1:20,000 to 1:30,000) and flightlines varied between the three historical photography projects.

After determining which historical photographs required rectification, the photographic paper prints or diapositives were digitally captured by using a high-precision image scanner with a scanning aperture of 28 microns, unless otherwise noted from the contributing agencies (for example, the California Tahoe Conservancy provided scanned imagery). Because camera data for historical photographs were generally incomplete or nonexistent, scanned images with clear fiducial marks were precisely measured for generating a camera calibration file for each date of imagery. The transformation software used to generate the camera-calibration file also calculated an approximate photograph scale. After transformation, all image coordinates had their origin at the image center.

Existing standard DOQs were primarily (although not exclusively) used as control for the scanned historical images as a substitute for aerotriangulation, since historical flight control records were either insufficient or no longer available. The selected control points had to be visible on both the existing DOQ and the historical image. By displaying the two images on screen, ideally nine or more points of common, well-defined features in both images were selected and measured to provide ground control for each historical image. At least two points were selected on an image edge to ensure commonality with two or more adjoining overlap and side images. It is important to note that although a historical image can be controlled with a minimum of four points, the selection of more points ensures that the horizontal accuracy of the final HDO is more consistent with the control data.

Occasionally, the visual and geographic differences between the historical image and the control DOQ were so great that correlation of common features for control points was difficult, if not impossible. This problem required using a control source closer to the date of the source historical photograph. Alternative control sources included historical and current topographic maps (hard-copy or digital) that were compiled using aerial photographs that are temporally closer to the date of the historical photographs being used to make the HDO. 


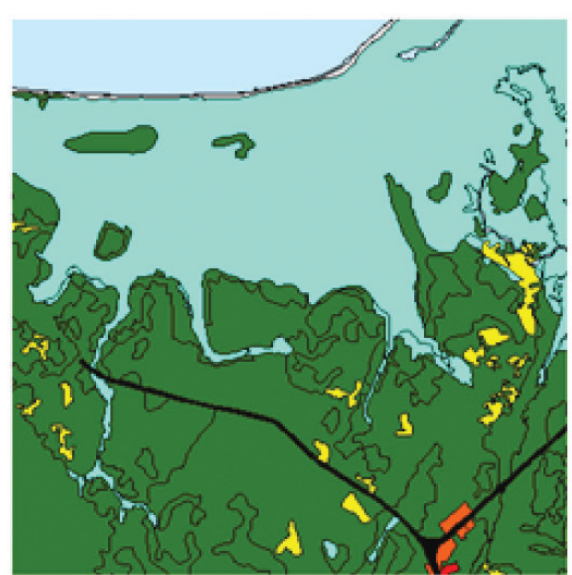

1940

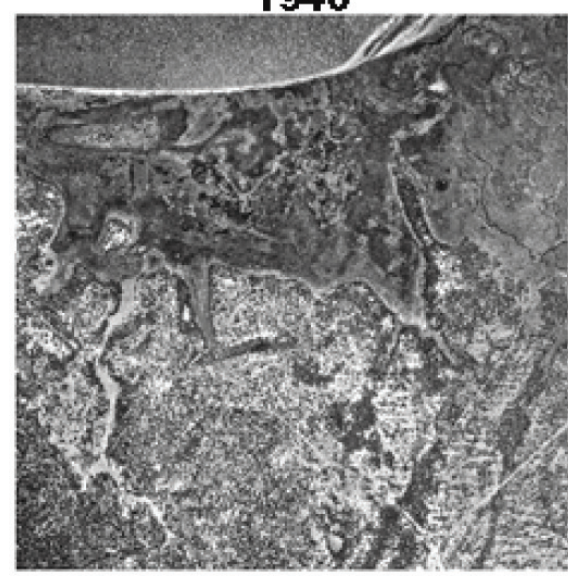

Water

Wetland

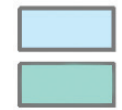

Mech. disturbed

Transportation

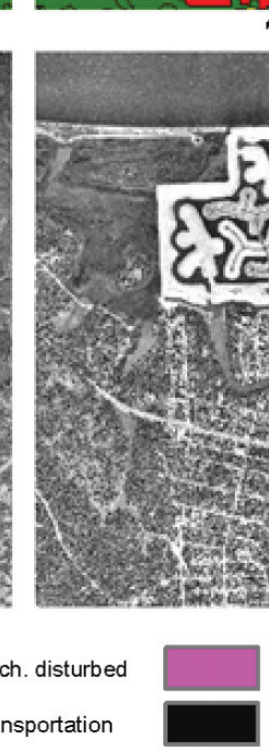

1969

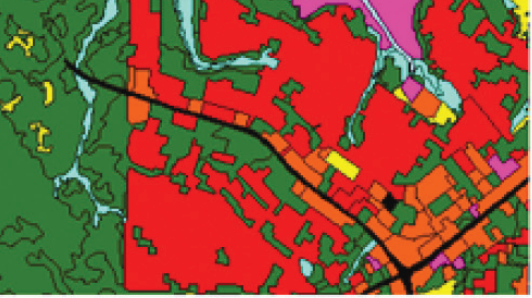

1969

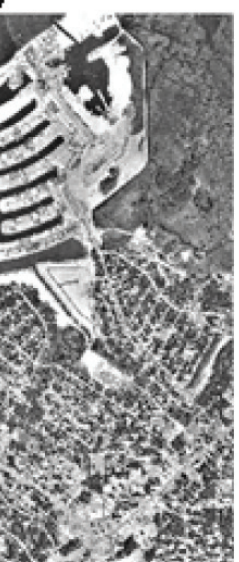

H. 023

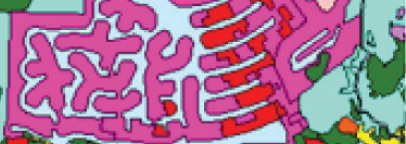
में

Figure 2. Four dates $(1940,1969,1987,2002)$ of temporal land-use/land-cover data derived from HDOs and satellite imagery. These datasets were used to measure the extent and effects of anthropogenic disturbances in the southern Lake Tahoe basin.

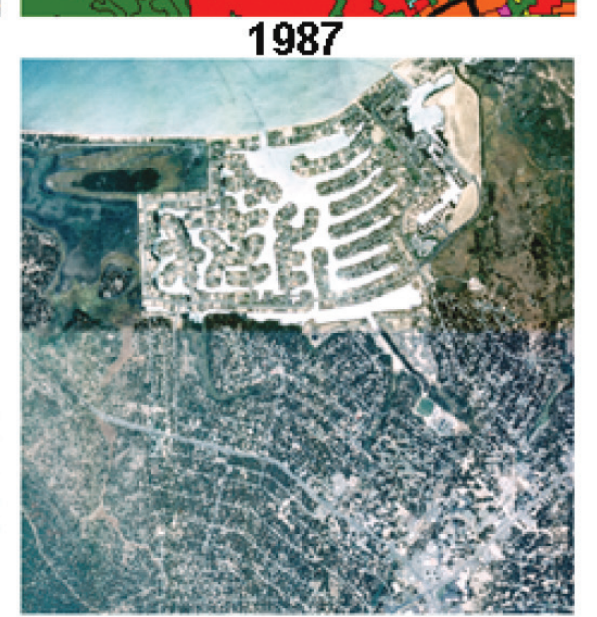

Grass/shrubland

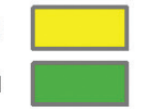

Recreationa

Commercial
Forest/woodland

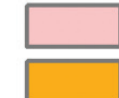

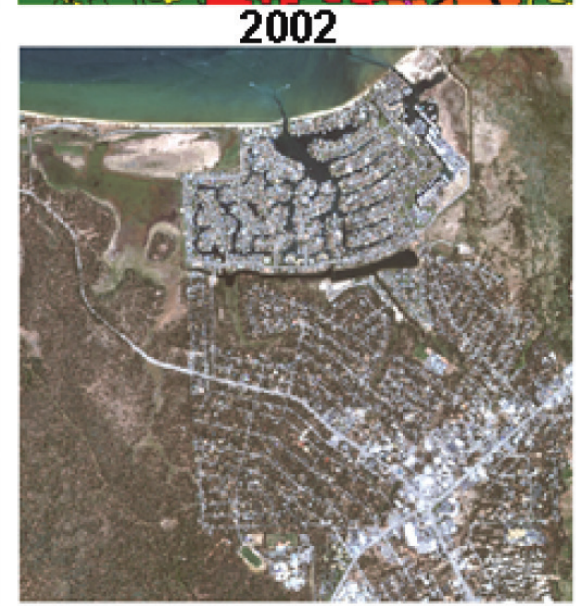

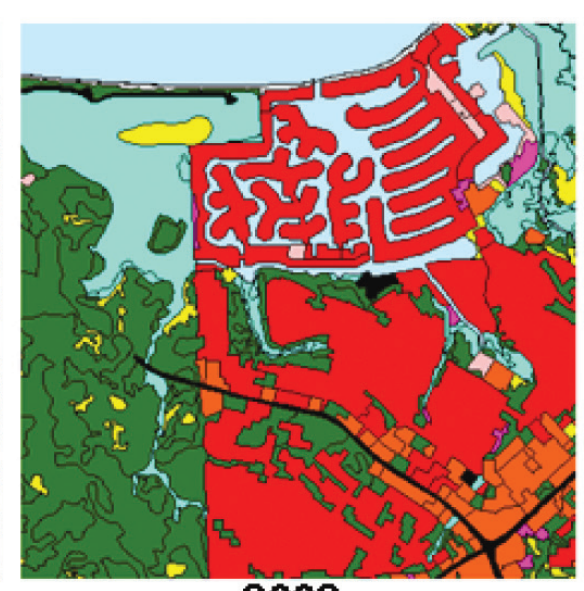

Residential 
Camera-calibration files, control files, a DEM (which is generally the same elevation source as that used to produce the existing standard DOQ selected for control), and a scanned historical image are the inputs for the USGS-developed Digital Orthophoto Processing System (DOPS), which was used to perform orthorectification. A parameter (.par) file containing relevant project information was generated by the DOPS. Essential data describing each individual chip to orthorectify was recorded in the parameter file to ensure the proper interaction between inputs and for later program execution.

Once rectified, the individual image chips required mosaicking to construct the 3.75-minute HDOQ tiles. Image chips were commonly used repeatedly where chip coverage extended into multiple 3.75-minute quadrangles. When data gaps were present in the mosaicked HDOQ as a result of underestimating the image-chip coverage, the original chipdomain size was adjusted to extend the image area and was again rectified and mosaicked. The mosaic software application locally adjusted the radiometric values of the images at join lines (appearing as seam lines in the software interface) to minimize tonal variations between adjacent images. After the image chips were mosaicked, the HDOQ overlap was calculated and trimmed, and the HDOQ corner crosses were embedded in the mosaicked image. Roughly 100 pixels (or 100 meters) of overlap were added to each 3.75-minute tile to facilitate combining the files into larger regions without data gaps. Finally, a standard USGS keyword header was created for the HDOQ to include information such as the aerial-photosource provider and acquisition date.

Final quality-assurance/quality-control measures consisted of reviewing the DOPS program execution and accuracy reports, HDO/HDOQ header verification, on-screen visual inspection of each individual HDO/HDOQ, and a comprehensive check of all HDO/HDOQs within the project, including the examination of image-adjacency geometry and general image radiometry.

\section{Accuracy}

The horizontal accuracy of a HDO is, at best, equivalent to the DOQ or map from which the ortho control was derived. Control point measurement errors and the difficulty in locating an adequate number of quality control points between the photography and the control data can decrease the final horizontal accuracy of a HDO.

A secondary series of considerations in assessing the accuracy of the HDO are the accuracies of the DEMs, DOQs, and/or maps from which the HDO was rectified. The positional accuracy for DOQs is described as follows (U.S. Geological Survey, 1996): "Digital orthophoto quadrangles and quarter-quadrangles must meet horizontal National Map Accuracy Standards (NMAS) at 1:24,000 and 1:12,000 scale, respectively. The NMAS specify that 90 percent of the welldefined points tested must fall within 40 feet (1/50 inch) at
$1: 24,000$ scale and 33.3 feet $(1 / 30$ inch) at 1:12,000 scale. The vertical accuracy of the source DEM must be equivalent or better than a level $1 \mathrm{DEM}$, with a root-mean-square error (RMSE) of no greater than 7.0 meters. The DOQ RMSE is the square root of the average of the squared discrepancies. These discrepancies are the differences in coordinate (X and $\mathrm{Y}$ ) values determined during aerotriangulation or by an independent survey of higher accuracy. All remaining inputs and processes (for example, aerotriangulation control and methodology, scanner and sensor calibrations) used in digital orthophoto production must be sufficiently accurate to ensure that the final product meets NMAS." After rectification of a standard USGS DOQ, DOPS software tools were used to determine the accuracy of the DOQ. Additional information on DOQ accuracy is provided in the Orthophoto Accuracy (ORACC) User Manual (U.S. Geological Survey, 1993). The ORACC software within DOPS tests the accuracy of the DOQ and generates a file containing the horizontal RMSE. ORACC standards provide the basis for the positional accuracy for the production of the HDOs, but the resulting RMSE merely tests how well the HDOs match the DOQ control. Residuals varied across the study area based on control point measurement errors and the difficulty in locating an adequate number of quality control points. Additionally, the accuracy of the control data (primarily, DOQs) varied across the Lake Tahoe Basin (based on issues such as topography). For these reasons, we are unable to make a definitive statement of accuracy for these data. Ultimately, additional ground or Global Positioning System (GPS) control data independent of a standard DOQ may be used to better assess the horizontal accuracy of a HDO and may allow us to make a definitive accuracy statement.

\section{Data Download}

Three datasets are available: 1940 HDOs for the southern Lake Tahoe Basin, 1969 HDOs for the entire Lake Tahoe Basin, 1987 HDOs for the southern Lake Tahoe Basin. The 2002 Ikonos imagery that covers the entire Lake Tahoe Basin is not available for download in this series due to restrictions in the licensing agreement. The data have been clipped into files that spatially resemble the 3.75-minute USGS quarter quadrangles, and have roughly 100 pixels (100 meters) of overlap to facilitate combining the files into larger regions without data gaps (http://pubs.usgs.gov/ds/376/data/). The files are named after 3.75-minute USGS quarter quadrangles that cover the same general spatial extent (fig. 3 and fig. 4). These files are available in the ERDAS Imagine (.img) format.

\section{Acknowledgments}

Development of this dataset was funded jointly by the Southern Nevada Public Land Management Act (SNPLMA) funds managed by the Bureau of Land Management and 
Figure 3. Footprint of $\mathrm{HDO} /$ HDOQ data for the southern Lake Tahoe basin for 1940 and 1987. The HDO/HDOOs have been clipped into files that spatially approximate the 3.75-minute USGS quarter quadrangles

[left blue boxes: 1940 data links; right blue boxes: 1987 data links].

\section{Lake Tahoe Basin} 1969 HDOQs

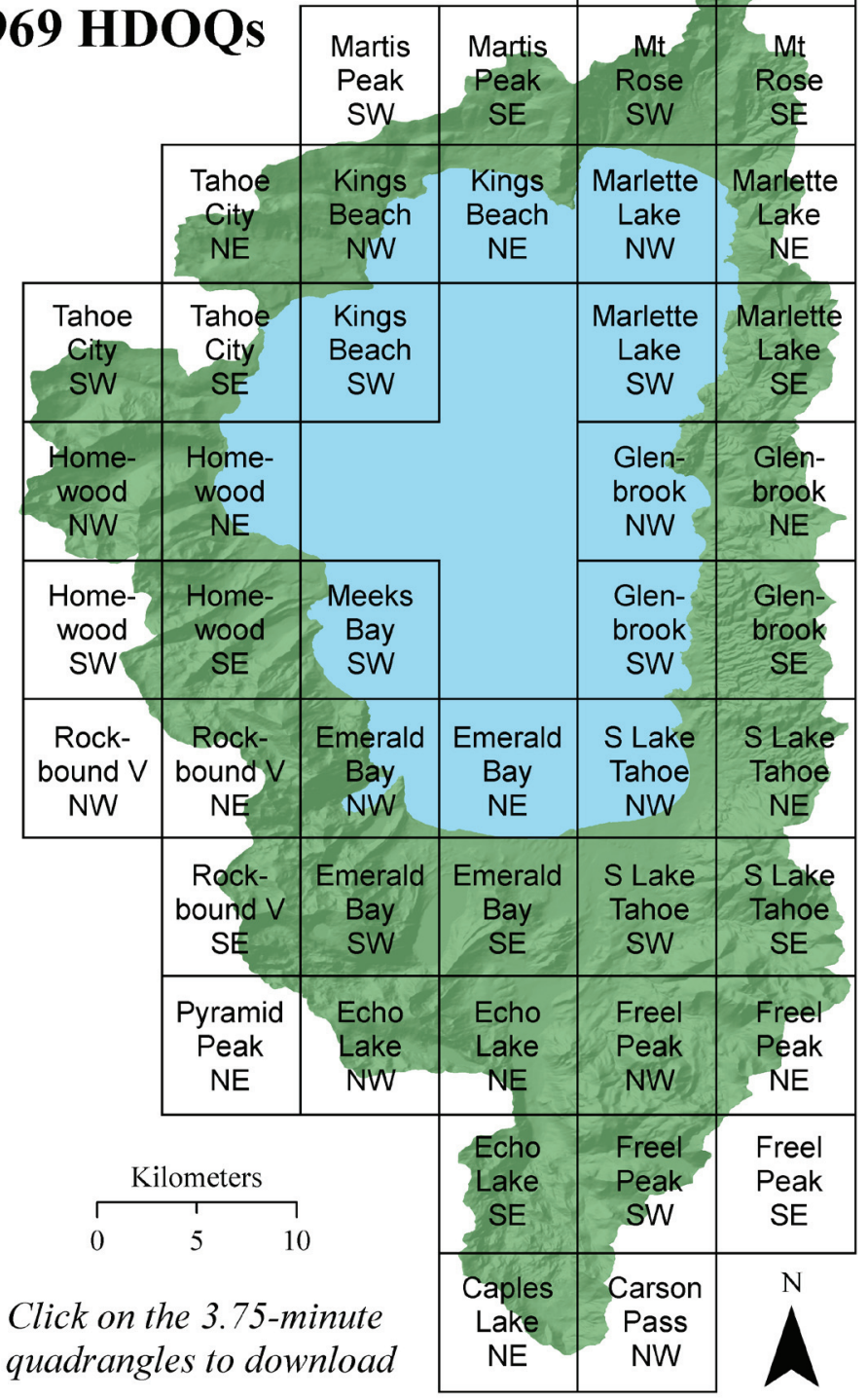

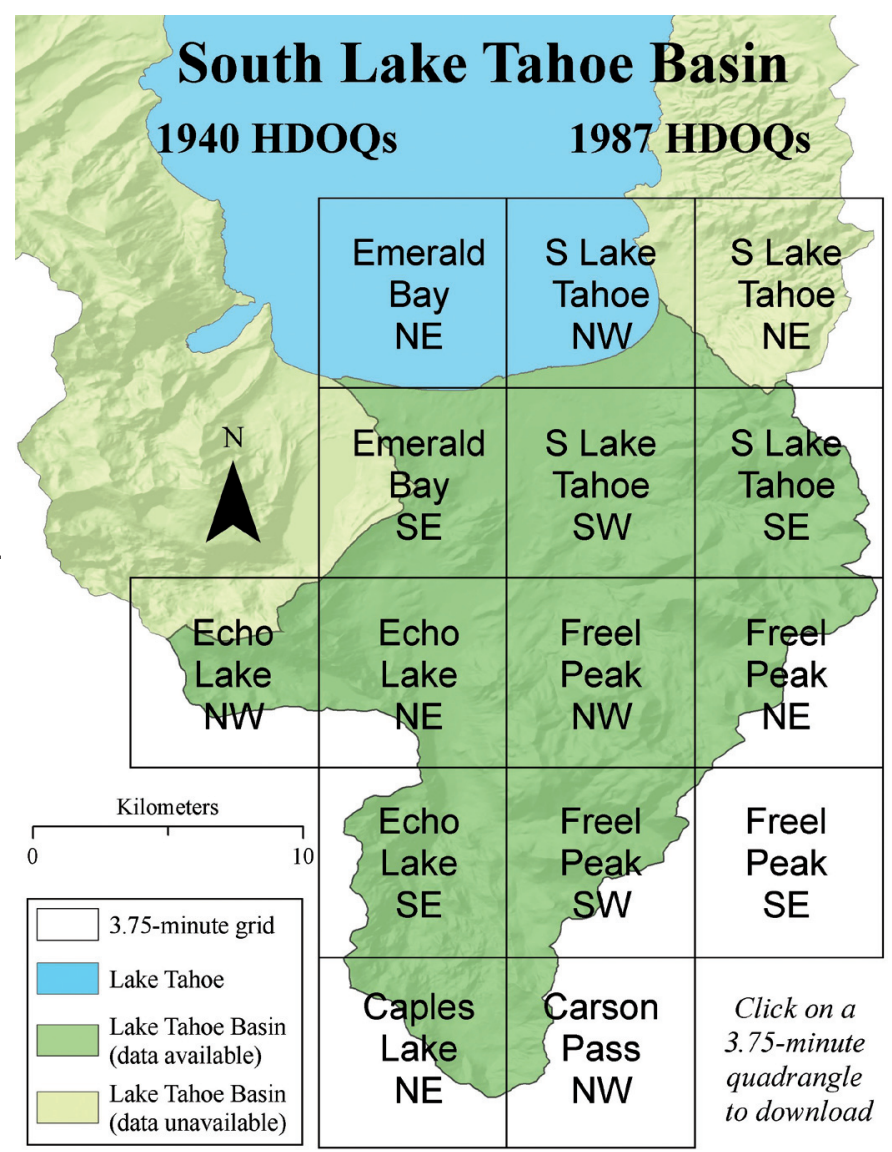

Figure 4. Footprint of $\mathrm{HDO} /$ HDOO data for the Lake Tahoe basin for 1969. For 1969, HD00s were created for the entire Lake Tahoe basin, compared to the smaller footprints for 1940 and 1987. The data have been clipped into files that spatially approximate the 3.75-minute USGS quarter quadrangles.

Some data may be absent due to unacceptable rectification errors. 
from the USGS Land Remote Sensing program. Portions of the photography collection used to create orthoimagery were donated by The California Tahoe Conservancy. Finally, the creation of the orthoimagery collection could not have been completed without the contribution of former USGS employee, Tom Coons.

\section{References}

Raumann, C.G., and Cablk, M.E., 2008, Change in the forested and developed landscape of the Lake Tahoe basin, California and Nevada, USA, 1940 -2002: Forest Ecology and Management 255, p. 3424-3439.

U.S. Geological Survey, 1996, Technical instructions, standards for digital orthophotos: [http://rockyweb. cr.usgs.gov/nmpstds/doqstds.html (last accessed September 16, 2008)].

U.S. Geological Survey, 1993, Technical instructions, ORACC users manual: Reston, Virginia. 
